\title{
Lack of evidence for KRAS oncogenic mutations in triple-negative breast cancer
}

\author{
Alfonso Sánchez-Muñoz 1,3, Elena Gallego 2,3, Vanessa de Luque³, Luís G Pérez-Rivas33,4, Luís Vicioso2,3, Nuria Ribelles 1,3, \\ José Lozano 3,4 and Emilio Alba*1,3
}

\begin{abstract}
Background: Mutational analysis of the KRAS gene has recently been established as a complementary in vitro diagnostic tool for the identification of patients with colorectal cancer who will not benefit from anti-epidermal growth factor receptor (EGFR) therapies. Assessment of the mutation status of KRAS might also be of potential relevance in other EGFR-overexpressing tumors, such as those occurring in breast cancer. Although KRAS is mutated in only a minor fraction of breast tumors (5\%), about $60 \%$ of the basal-like subtype express EGFR and, therefore could be targeted by EGFR inhibitors. We aimed to study the mutation frequency of KRAS in that subtype of breast tumors to provide a molecular basis for the evaluation of anti-EGFR therapies.

Methods: Total, genomic DNA was obtained from a group of 35 formalin-fixed paraffin-embedded, triple-negative breast tumor samples. Among these, 77.1\% (27/35) were defined as basal-like by immunostaining specific for the established surrogate markers cytokeratin (CK) 5/6 and/or EGFR. KRAS mutational status was determined in the purified DNA samples by Real Time (RT)-PCR using primers specific for the detection of wild-type KRAS or the following seven oncogenic somatic mutations: Gly12Ala, Gly12Asp, Gly12Arg, Gly12Cys, Gly12Ser, Gly12Val and Gly13Asp.

Results: We found no evidence of KRAS oncogenic mutations in all analyzed tumors.

Conclusions: This study indicates that KRAS mutations are very infrequent in triple-negative breast tumors and that EGFR inhibitors may be of potential benefit in the treatment of basal-like breast tumors, which overexpress EGFR in about $60 \%$ of all cases.
\end{abstract}

\section{Background}

Breast cancer is a complex and heterogeneous disease that includes tumors of variable prognosis and clinical response to treatments [1]. Standard breast tumor classification has long relied on morphological and anatomical criteria such as tumor size and extension (TNM staging), histopathological features (tumor grade) and expression of protein markers such as the estrogen receptor (ER), progesterone receptor (PR) and the human epidermal growth factor receptor 2 (HER2) oncogene [1,2]. While these parameters may correlate well with survival in some patients, their value as prognostic and predictive factors is limited given the fact that patients with similar tumors often have a different clinical progression and treatment response $[1,2]$. The existence of such differences in the

*Correspondence: ealbac@uma.es

1 Servicio de Oncología Médica, Hospital Universitario Virgen de la Victoria, Campus de Teatinos s/n, 29010 Málaga, Spain

Full list of author information is available at the end of the article clinical outcome of breast cancer patients can be explained by intrinsic tumor variability at the molecular level [3-7]. In two landmark studies, Perou et al. and Sorlie et al. [3,5] identified five distinct "intrinsic" subtypes of breast cancer by hierarchical cluster analysis of microarray gene expression data: luminal A and luminal $\mathrm{B}$ [both estrogen receptor-positive $(E R+)$ ], HER2 overexpressing (HER2+), normal breast-like and basal-like. These subtypes are associated with different clinical outcomes, with the HER2+ and basal-like subtypes being more agressive and having poor prognoses $[5,8]$. The term triple-negative is frequently used as synonymous for basal-like, since these tumors lack expression of ER, PR and HER2 $[9,10]$. However, not all triple-negative tumors are basal-like while most basal-like tumors are triple-negative $[4,10]$. Triple-negative tumors are found in only $15 \%$ of all breast cancer patients and the incidence varies by race and age. In particular, the basal subtype represents $10-14 \%$ of all 
breast cancers in Caucasian women and 20-37\% in African American patients [11,12]. Despite their low incidence, triple-negative breast cancer represent a major clinical challenge due to the high mortality associated with the disease [4].

At the immunohistochemical level, the basal-like subtype express a group of proteins similar to those expressed in the basal -hence the name- ephithelial cells of the mammary gland. These include cytokeratins (CK) 5, 6 and 17, epidermal growth factor receptor (EGFR), caveolin, Ki-67, c-KIT and $\alpha \beta$-crystalin $[3,5,13,14]$. Most of basal-like tumors are highly proliferative, show high histologic grade and are associated with a higher incidence of mutations in BRCA1 and TP53 [15]. Clinically, these tumors are agressive and tend to form metastasis in the lungs or in the brain $[16,17]$. Similar to the HER2+, the triple-negative subtype shows responsiveness to chemotherapy with taxanes and anthracyclines [18,19]. It is typically associated with a bad prognostic, as defined by reduced disease-free survival (DFS) and overall survival (OS) rates [16,17]. Hormone therapies and anti-HER2 therapies are innefective in the treatment of triple-negative breast cancer and thus, searching for new drug targets selective for this subtype of tumors is a major challenge in modern oncology.

Near $60 \%$ of basal-like tumors express the epidermal growth factor receptor (EGFR) and, therefore are potential targets of EGFR inhibitors such as the monoclonal antibodies cetuximab and panitumumab or the small molecule inhibitors gefitinib and erlotinib. [20,21]. Signals initiated at the EGFR are transmited intracellularly by members of the GTPase Ras family of proteins, which function as molecular switches in the transduction of proliferative and differentiating signals [22]. Members of this family include $K R A S, H R A S$, NRAS and RRAS, with $K R A S$ being a mammalian homolog of the Kirsten ras oncogene [23]. Ras proteins are activated by guanine nucleotide exchange factors (GEFs), allowing release of bound GDP and binding of cytosolic GTP. Once activated, they function at the plasma membrane by recruiting several signaling proteins such as RAF, PI 3-kinase and RalGDS [24]. The low intrinsinc GTPase activity of Ras is increased by interaction with GAP (GTPase activating protein) which hydrolizes bound GTP and turns off Ras signaling [24]. Several oncogenic mutations have been described in the KRAS gene wich result in its constitutive activation and in autonomous, non-regulated proliferation of the transformed cells as well as their resistance to apoptosis [22]. Somatic KRAS mutations are found in pancreatic cancer (60\% of tumors), colon cancer (32\%), lung cancer (17\%) and, with a much lower incidence (5\%), in leukemias and breast cancer [24]. Germline mutations in KRAS are associated with Noonan syndrome and cardio-facio-cutaneous syndrome $[25,26]$. Anti-EGFR therapies relay on the presence of wild-type Ras to be effective since oncogenic Ras transmits proliferative and antiapoptotic signals independently of the EGFR activation $[22,24]$. For that reason, treatments with anti-EGFR drugs such as cetuximab and panitumumab have incorporated routine assessment of KRAS status prior to administration [27]. The effectiveness of EGFR inhibitors in metastatic colon cancer has been reported in several studies measuring the response rate (RR) and DFS [27-35]. Importantly, the effectiveness of both drugs is limited to those tumors harboring no oncogenic mutations in $K R A S$ [28].

Since most basal-like tumors express EGFR, it seemed of interest to investigate the mutational status of KRAS in such tumors to provide scientific evidence for the evaluation of anti-EGFR therapies in the management of triplenegative breast cancer. Our results indicate that most, if not all, triple-negative tumors harbor wild-type $K R A S$, supporting the use of EGFR inhibitors, alone or in combination with other drugs, for their treatment.

\section{Methods \\ Samples}

Tumor samples were obtained from 35 patients with early breast cancer of the basal-like subtype who had undergone treatment at the Hospital Clínico Universitario Virgen de la Victoria (HCUVV, Málaga, Spain). Tumors were classified as basal-like following the criteria stablished by Nielsen et al., i.e., expression of cytokeratins 5/6 and/or EGFR together with lack of expression of ER and HER2 [20]. These criteria have demonstrated $76 \%$ sensitivity and $100 \%$ specificity for the identification of basal-like breast tumors as defined by gene expression profiling. The corresponding formalin-fixed, paraffin-embedded tissues were obtained from the Pathology Department at HCUVV and processed by immunohistochemistry to check the expression of ER, EGFR and cytokeratins. Tumor areas were marked by direct visualization in 5 serial $10-\mu \mathrm{M}$-thick sections and manually microdissected with a razor blade. To obtain genomic DNA, dissected samples were disolved in xylene to remove paraffin and processed with the QIAamp DNA FFPE Tissue kit (Qiagen) following the manufacturer's instructions. DNA was quantitated spectrophotometrically by measuring absorbance at $\lambda=260 \mathrm{~nm}$ in a Nanodrop system. All DNA samples included in this study had an $\mathrm{A}_{260} / \mathrm{A}_{280}$ ratio higher than 1.8. As a positive control for the mutation analysis, we also included genomic DNA prepared from two colon cancer biopsies known to be positive for KRAS mutation. Experimental procedures were approved by the Scientific and Ethical Review Board of the HCUVV. 


\section{Immunohistochemistry}

Immunohistochemical staining was performed on 3- $\mu \mathrm{m}$ sections of paraffin blocks containing tumour tissue. HER2 immunohistochemistry was performed following the instructions included in the HercepTest ${ }^{\mathrm{m}}$ kit (Dako). For all other antigens, epitopes were retrieved by microwaving the sections in citrate buffer $\mathrm{pH} 6.0$ for $20 \mathrm{~min}$. Immunohistochemistry was carried out in a Tech Mate Horizon autoimmunostainer (Dako, Copenhagen, Denmark) using the Dako Real EnVision system for signal detection. The following antibodies were from Dako: estrogen receptor (clone 1D5), progesterone receptor (clone PgR636) and HER2 (HercepTest ${ }^{\mathrm{m}}{ }^{\mathrm{H}}$ ). The anti-CK5/6 antibody (clone D5/16B4) was from Boehringer Biochemica). EGFR expression was determined with the EGFR pharmaDx ${ }^{\text {mit }}$ kit for autostainer (Dako). For ER and PR immunoreactivity, the cut-off value of $10 \%$ was used to divide cases into negative and positive groups. HER2 expression was scored following the guidelines of the HercepTest ${ }^{\mathrm{m}}$ kit and interpreted as negative when the staining intensity was 0 or $1+$ and positive when it was $2+$ or $3+$. Membrane staining was used as the evaluable parameter to determine EGFR expression with the EGFR pharmaDx $^{\mathrm{mm}}$ kit. Positivity for EGFR expression was defined as any membrane staining above background level in at least $1 \%$ of tumor cells. Absence of staining was reported as negative. For the basal marker CK 5/6, positivity was defined as detection of any stained invasive malignant cells.

\section{Mutation analysis}

The Therascreen KRAS kit (Roche Diagnostics) was used to determine the mutational status of KRAS in the samples. Briefly, 50-100 ng of total genomic DNA was analyzed by Real Time (RT)-PCR using mutation-specific Scorpions primers. The kit allowed detection of the following mutations: Gly12Ala (GGT>GCT)522, Gly12Asp (GGT>GAT)521, Gly12Arg (GGT>CGT)518, Gly12Cys (GGT>TGT)516, Gly12Ser (GGT>AGT)517, Gly12Val (GGT>GTT)520, Gly13Asp (GGC>GAC)532. All experiments included both a positive (each mutant DNA) and a negative (no template) control reaction. Reactions were carried out in 96-well plates in an ABI 7500 Real-Time PCR system (Applied Biosystems). Threshold cycle $\left(C_{t}\right)$ was plotted against normalized reporter $\left(\mathrm{R}_{\mathrm{n}}\right)$ and the $\Delta \mathrm{C}_{\mathrm{t}}$ was calculated by the formula: $\Delta \mathrm{C}_{\mathrm{t}}=\mathrm{C}_{\mathrm{ts}}-\mathrm{C}_{\mathrm{tc}}$, were $\mathrm{C}_{\mathrm{ts}}$ and $\mathrm{C}_{\mathrm{tc}}$ are the $\mathrm{C}_{\mathrm{t}}$ of the sample and the positive control, respectively. Values of $C_{t c}$ were in the range of 29-35. The obtained $\Delta \mathrm{C}_{\mathrm{t}}$ values were compared with the reference values provided in the kit to classify the samples as positive or negative for each $K R A S$ mutation.

\section{Results and discussion}

Thirty-five archived paraffin blocks containing tumor samples from different breast cancer patients were ini- tially selected as triple-negative on the basis of their lack of immunoreactivity for the surrogate markers ER, PR and HER2 (Table 1 and Fig. 1). We then performed additional immunostaining with antibodies against CK5/6 and EGFR to identify the subgroup of basal-like tumors [20]. Such analysis revealed that $77.1 \%(27 / 35)$ of the tumors were basal-like. Table 2 summarizes the immunohistological characteristics of all tumors analyzed in this study. Expression of CK5/6 was detected in $63.0 \%$ of all tumors classified as basal-like while $92.6 \%$ stained positive for EGFR (Table 2). The observed proportion of basal-like tumors expressing CK5/6 is in good agreement with that reported by other groups $[9,20]$ however, we found a higher frequency of EGFR expression when compared with the $57 \%$ and $27 \%$ values reported by Nielsen $e t$ al. [20] and Kreike et al. [9], respectively. Of note, the EGFR status in breast cancer has not been examined as extensively as in other types of cancer and its reported overexpression ranges from $14 \%$ to $91 \%$ [36-38]. EGFR expression has been associated with BRCA1-mutated tumors and basal-like phenotype in several studies [37,39-41]. In addition, some observations suggest that EGFR upregulation is an early event in breast tumorigenesis since EGFR overexpression can be observed in premalignant lesions [37]. As has been suggested by some investigators, a more detailed study on the activation status and subcellular localization of wild-type EGFR, in both primary and metastatic tumors, is needed to evaluate EGFR expression as a predictive marker for response to anti-EGFR therapies [42].

Although the subtyping of our group of 35 tumor samples did not emerged from gene expression profiling data, they were defined as triple-negative (nonbasal) or basallike by immnostaining with a set of four surrogate markers that has been demonstrated to be $76 \%$ sensitive and $100 \%$ specific [20]. Here, we will use the term triple-negative in reference to the full set of 35 tumor samples (ER-, PR- and HER2-) while the term basal-like will be reserved for the subset of samples that, in addition to being ER-, PR- and HER2-, are positive for CK5/6 and/or EGFR staining.

Breast cancer cell lines stablished from basal-like tumors are more sensitive to EGFR inhibitors and carboplatin -alone or in combination- than those stablished from luminal tumors [32]. Both drugs have an additive effect when added in combination [32] and preclinical data argue in favor of anti-EGFR therapies in this subtype of tumors. Oncogenic Ras proteins can signal cell proliferation even in the absence of EGFR activation and thus, molecular testing of human KRAS mutations is of great relevance in the identification of patients that may benefit from anti-EGFR therapies. In a study reported by Hollestelle et al. [43]KRAS mutations were found in 5 out of 40 different breast cancer cell lines (13\% incidence). Overall, $K R A S$ mutations are infrequent in breast cancer, repre- 
Table 1: Immunohistochemical data.

\begin{tabular}{|c|c|c|c|c|}
\hline Sample \# & ID & CK5/6* & EGFR $^{*}$ & Basal-like= \\
\hline 1 & 757688 & - & + & yes \\
\hline 2 & 767740 & + & + & yes \\
\hline 3 & 832343 & - & + & yes \\
\hline 4 & 608891 & + & + & yes \\
\hline 5 & 857666 & + & - & yes \\
\hline 6 & 804529 & + & + & yes \\
\hline 7 & 555943 & + & + & yes \\
\hline 8 & 452803 & - & + & yes \\
\hline 9 & 481252 & + & + & yes \\
\hline 10 & 222867 & - & - & no \\
\hline 11 & 402341 & - & + & yes \\
\hline 12 & 760011 & + & + & yes \\
\hline 13 & 834492 & - & + & yes \\
\hline 14 & 778794 & - & - & no \\
\hline 15 & 717674 & + & + & yes \\
\hline 16 & 768943 & - & - & no \\
\hline 17 & 438696 & - & + & yes \\
\hline 18 & $\mathrm{CH}$ & + & + & yes \\
\hline 19 & 198346 & + & + & yes \\
\hline 20 & 853477 & + & + & yes \\
\hline 21 & 265886 & - & - & no \\
\hline 22 & 841511 & + & + & yes \\
\hline 23 & 708805 & - & + & yes \\
\hline 24 & 856202 & - & + & yes \\
\hline 25 & 841511 & + & + & yes \\
\hline 26 & 852333 & + & + & yes \\
\hline 27 & 405573 & + & - & yes \\
\hline 28 & 194302 & - & - & no \\
\hline 29 & 108707 & - & - & no \\
\hline 30 & 43742 & + & + & yes \\
\hline 31 & 560504 & - & - & no \\
\hline 32 & 779157 & - & + & yes \\
\hline 33 & 107512 & - & - & no \\
\hline 34 & 772351 & - & + & yes \\
\hline 35 & 844953 & + & + & yes \\
\hline
\end{tabular}

*positivity detected by immunohistochemistry

=basal-like $=$ CK5 $/ 6+$ and/or EGFR+

Abbreviations: ID, identification 
Table 2: Frequency of immunostaining and KRAS mutations among breast cancer tumors.

\begin{tabular}{cccccc}
\hline Subtype & Samples & CK5/6+ (\%) & EGFR+ (\%) & CK/EGFR+ (\%)* & KRAS mut (\%) \\
\hline TN & 35 & $17(48.6)$ & $25(71.4)$ & $15(42.8)$ & $0(0.0)$ \\
BS & 27 & $17(63.0)$ & $25(92.6)$ & $15(55.5)$ & $0(0.0)$ \\
\hline *Positive staining for both CK5/6 and EGFR & & &
\end{tabular}

Abbreviations: TN, triple-negative; BS, basal-like; CK, cytokeratin 5/6; KRAS mut, mutant KRAS

senting a mere $5 \%$ of all breast carcinomas [24]. However, it is not known if they are distributed randomly in all five molecular subtypes of breast cancer (luminal A, luminal B, HER2+, normal-like and basal-like) or concentrated in one or a few subtypes. In particular, $\sim 60 \%$ of the basallike tumors express EGFR and thus, they are an attractive target for EGFR inhibitors. Thus, we wanted to investigate if molecular testing of KRAS mutations would serve as a prognostic factor in adjuvant therapy recommendations for basal-like breast cancer patients.

To that aim, total genomic DNA obtained from each paraffin-embedded tumor was subjected to RT-PCR reactions with primers specifically designed to amplify and detect seven cancer-related somatic mutations in codons 12 and 13 of human KRAS [44,45]. Notably, none of the DNA samples could function as template for amplification of the KRAS oncogenic mutations, indicating that the full set of 35 triple-negative tumors expressed the wild-type protein (Table 2 and Fig. 2). As such, the wild-type KRAS gene could be amplified and detected in all 35 DNA samples. Also, genomic DNA from a colon carcinoma known to harbor a Gly12Cys mutation in $K R A S$ could be amplified and the mutation detected by RT-PCR (Fig. 2). This result indicates that the lack of KRAS mutations observed in the breast tumor samples were not due to a deficiency in the assay (Fig. 2). Therefore, we found no evidence of $K R A S$ somatic mutations in human triple-negative tumors as measured by a standarized assay $[44,45]$. We cannot exclude the possibility that a minimal number of cells, below the detection limit of the assay ( $<1 \%$ of tumor cells) harbor mutations in $K R A S$, however, we used the same diagnostic assay currently included in the clinical practice to select colorectal patients for anti-EGFR treatments. It is well known that KRAS mutations are infrequent in breast cancer [24] and our data further indicates that they are not distributed homogeneously and are uncommon, if not absent, in triple-negative tumors. In a recent study aimed at the identification of EGFR-associated expression profiles in different breast cancer subtypes, Perou and co-workers mentioned that, as a control, they sequenced 96 breast tumors and found no common mutations in $B R A F, H R A S$ and $K R A S$ [32]. While our results are in agreement with such findings, they represent, to the best of our knowledge, the first attempt to directly determine the incidence of $K R A S$ mutations in basal-like breast tumors and to discuss them in the context of anti-EGFR therapies.

Two randomized phase II trials have evaluated the role of cetuximab in triple negative breast cancer. In the TBCRC 001 study, eligible, pretreated patients received the anti-EGFR monoclonal antibody cetuximab alone, with planned crossover to cetuximab plus carboplatin upon progression (arm 1) or cetuximab combined with carboplatin from the very begining ( $\operatorname{arm} 2$ ). Monotherapy with cetuximab showed low clinical benefit (CB) and RR (10\% and $6 \%$, respectively) and was cancelled early due to lack of efficacy. Moreover, the combination of cetuximab plus carboplatin achieved a modest activity: $17 \% \mathrm{RR}$, and 31\% CB [46]. A different phase II trial showed a higher RR in triple-negative patients treated with the combination of irinotecan plus carboplatin and cetuximab versus those treated with irinotecan plus carboplatin (49\% vs $30 \%$ ) [46]. Both trials included unselected patients with heavily pretreated tumors. It should be noted that although most basal-like cancers do not express ER and HER2, $15 \%$ to $45 \%$ are reported to express at least one of these markers. On the other hand, not all triple negative cancers are of basal-like profile, only approximately $85 \%$ of ER- and Her2- cancers are classified as basal-like by microarray analysis [20].

Besides $K R A S$, alterations in the phosphatidylinositol 3-kinase (PI3K) pathway have been described in several types of cancer $[47,48]$. In particular, activating mutations in PIK3CA, the gene encoding for the p110 $\alpha$ catalytic subunit of PI3K, confers resistance to cetuximab-induced cell cycle arrest in colon cancer cell lines [49]. The cells are maximally resistant when $K R A S$ and PIK3CA are mutated simultaneously [49]. The PIK3CA mutation frequency in breast cancer reportedly varies between $8 \%$ and 40\% [50-53]. Kalinsky et al. found PI3KCA mutations in $32.5 \%$ of invasive breast primary tumors in a large cohort of 590 samples [52] and, interestingly they correlated with older age at diagnosis, lower tumor grade and stage, and lymph node negativity. In addition, patients with PIK3CA mutations had improved OS and breast cancer-specific survival [52]. In a different study with a smaller cohort of 292 breast cancer patients, activation of the PI3K pathway (by genetic alterations in the PIK3CA, $P T E N$ or $A K T$ genes) was found to be significantly associated with a basal-like phenotype, high tumor grade and 

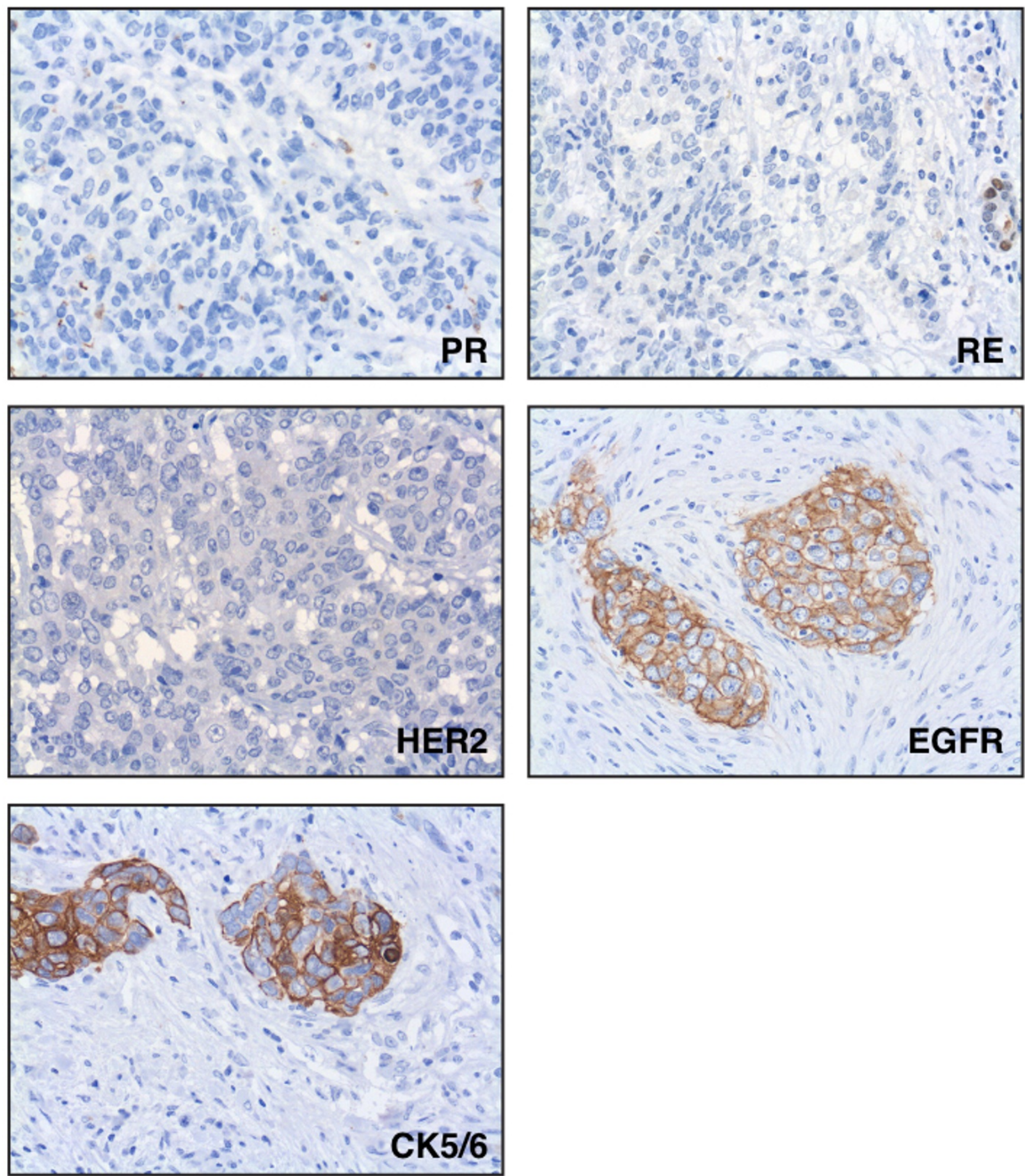

Figure 1 Representative immunohistochemistry of a basal-like breast tumor showing negative staining for the hormone receptors (ER and PR) and HER2 and positive staining for EGFR and CK5/6.

death from breast cancer. However, PIK3CA mutations alone did not correlate with any clinicopathological parameter [54]. Other studies have also reported contradictory -both favorable and poor- patient outcomes associated with PIK3CA mutations in breast cancer $[51,55]$.
While we have not addressed the mutational status of the PI3K pathway, the results from Kalinsky et al. suggest that activating mutations in PIK3CA will not confer resistance to anti-EGFR therapies. In fact, mutant cancer cells could be more sensitive to these type of agents. Alternatively, 


\section{A}

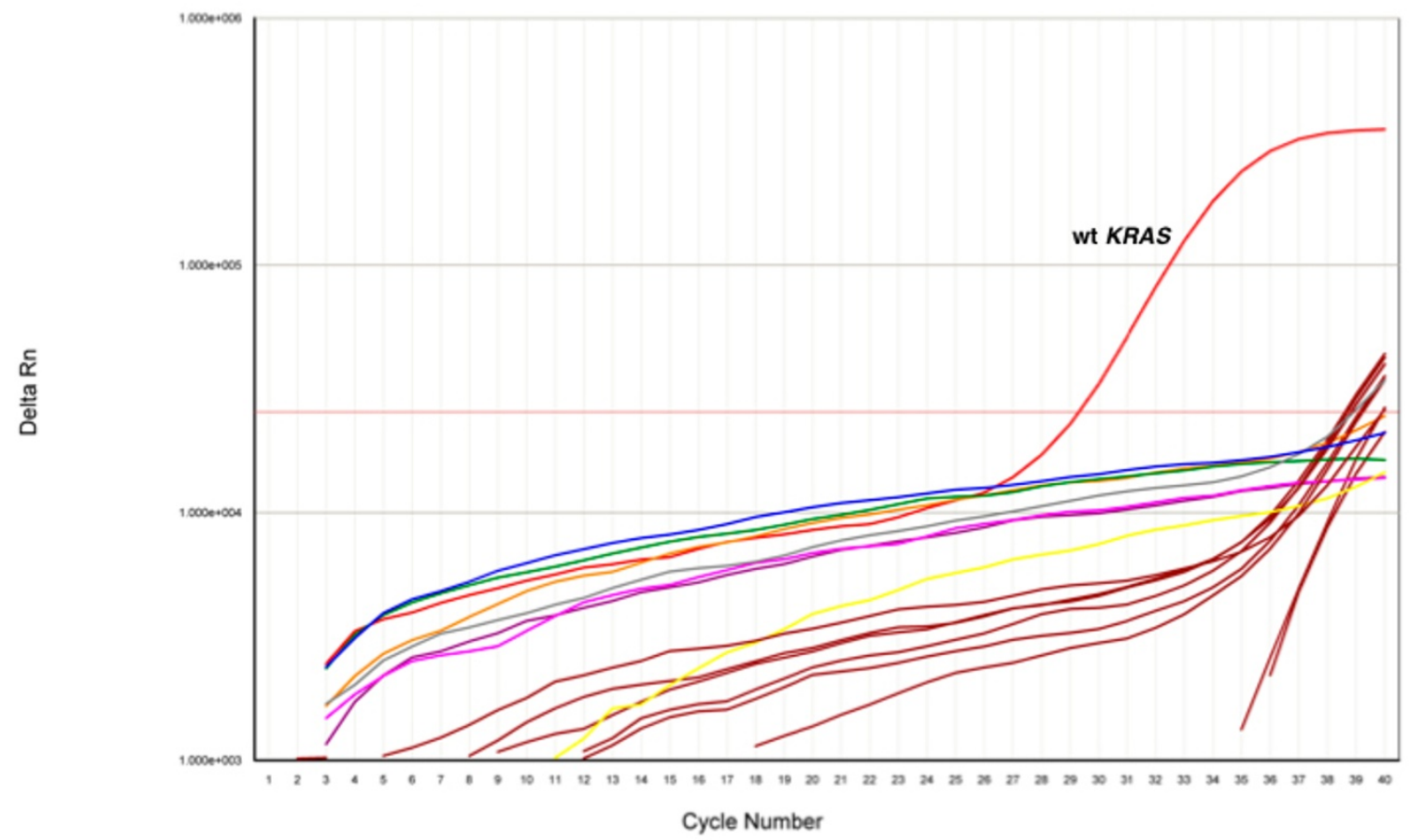

B

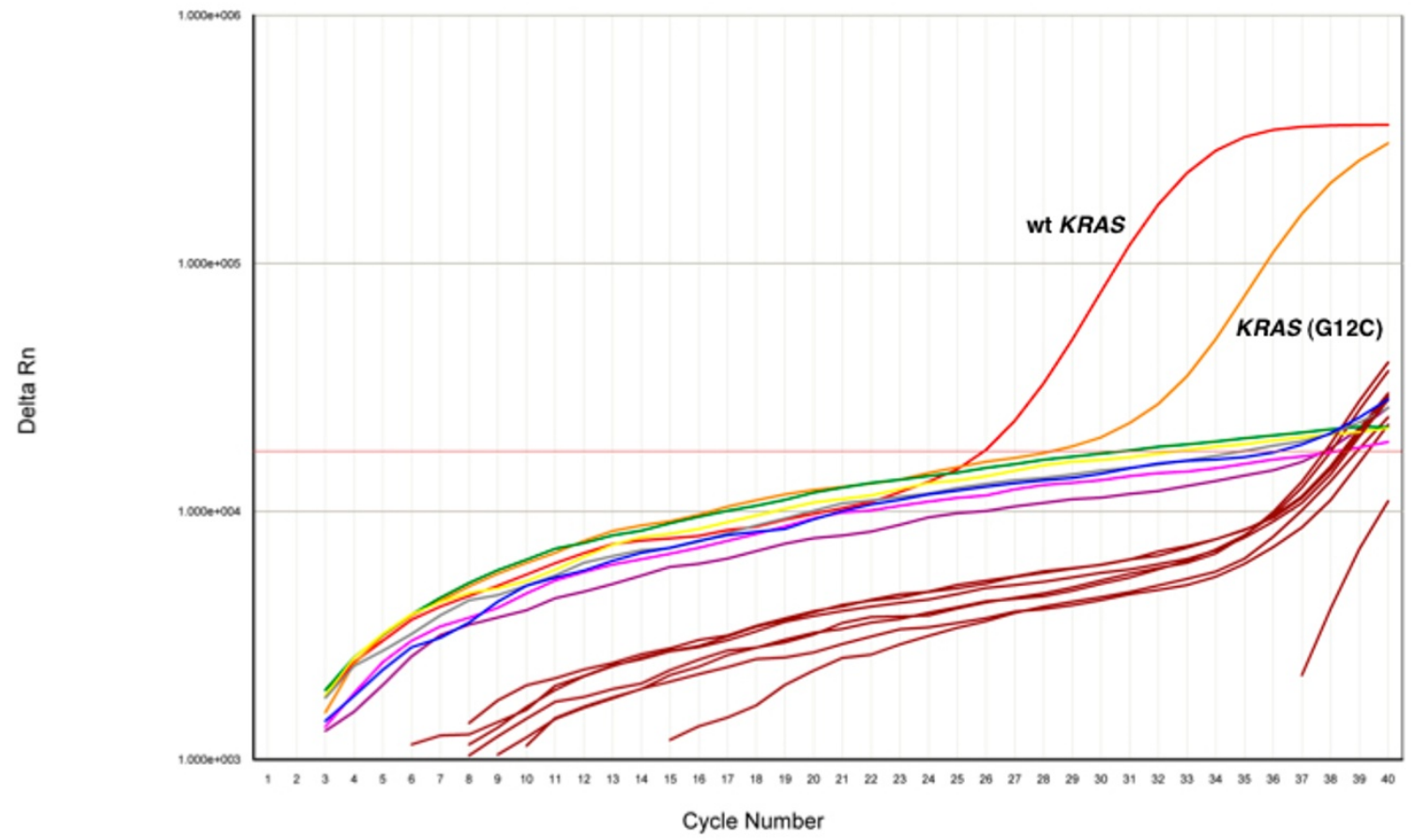

Figure 2 Detection of KRAS mutations by RT-PCR. A, The graph shows a representative amplification curve ( $\triangle \mathrm{Rn}$ vs cycle) from $100 \mathrm{ng}$ of genomic DNA prepared from a triple-negative tumor sample. RT-PCR reactions were performed with primers specifically designed to amplify wild-type KRAS (red) or the following mutants: Gly12Ala (green), Gly12Asp (blue), Gly12Arg (yellow), Gly12Cys (Pink), Gly12Ser (brown), Gly12Val (purple), Gly13Asp (grey). Brown lines correspond to the amplification profile of an internal control included in each reaction to check for false positives. B, As a positive control, genomic DNA was obtained from a colon carcinoma biopsy and subjected to RT-PCR as in A. Note the presence of the Gly 12 Cys mutation. 
identifying PIK3CA activating mutations in older patients could benefit them by minimizing the therapy. Additional studies are needed to clarify this issues.

In summary, despite the fact that most basal-like tumors included in our study expressed EGFR, we found no evidence of oncogenic mutations in $K R A S$. Therefore, we conclude that testing for $K R A S$ mutations is not necessary as a diagnostic factor in the treatment of basal-like breast cancer. Furthermore, the wild-type status of $K R A S$ observed in all samples analyzed here indicate that antiEGFR therapeutic strategies, such as those using monoclonal antibodies (cetuximab, panitumumab) or small molecule inhibitors (gefitinib, erlotinib), may be of potential benefit in the treatment of basal-like breast cancer.

\section{Conclusions}

Since we found no incidence of oncogenic KRAS mutations in basal-like tumors, our results indicates that therapies based on EGFR inhibition may be of benefit in the treatment of this particularly agressive subtype of breast tumors.

\section{List of abbreviations}

RR: response rate; DFS: disease-free survival; OS: overall survival; RT-PCR: real-time polymerase chain reaction; ER: estrogen receptor; PR: progesterone receptor; EGFR: epidermal growth factor receptor; HER2: human epidermal growth factor receptor 2; CK: cytokeratin.

\section{Competing interests}

The authors declare that they have no competing interests.

\begin{abstract}
Authors' contributions
ASM contributed to the study's design, analysis of data and manuscript draft ing. EG, VL and LPR processed the tumor samples. LV and NR participated in the study's design. JL contributed to the study's design, performed the mutational analysis and wrote the manuscript. EA contributed to the study's conception and design, interpretation of the data and manuscript writing. All authors read and approved the final manuscript.
\end{abstract}

\section{Acknowledgements}

This work was supported by Fondo de Investigaciones Sanitarias grant PI081797 (to E. A.) and Ministerio de Ciencia e Innovación grant BFU200766100 (to J. L.).

\section{Author Details}

'Servicio de Oncología Médica, Hospital Universitario Virgen de la Victoria, Campus de Teatinos s/n, 29010 Málaga, Spain, 2Servicio de Anatomía Patológica, Hospital Universitario Virgen de la Victoria, Campus de Teatinos s/n, 29010 Málaga, Spain, ${ }^{3}$ Laboratorio de Investigación Biomédica (LIB-IMABIS), Hospital Universitario Virgen de la Victoria, Campus de Teatinos s/n, 29010 Málaga, Spain and 4Dpto. de Biología Molecular y Bioquímica, Facultad de Ciencias, Universidad de Málaga, Campus de Teatinos s/n, 29071 Málaga, Spain

Received: 11 December 2009 Accepted: 13 April 2010 Published: 13 April 2010

\section{References}

1. Morrow PK, Hortobagyi GN: Management of breast cancer in the genome era. Annu Rev Med 2009, 60:153-165.

2. Cianfrocca M, Gradishar W: New molecular classifications of breast cancer. CA Cancer J Clin 2009, 59(5):303-313.
3. Perou CM, Sorlie T, Eisen MB, Rijn M van de, Jeffrey SS, Rees CA, Pollack JR, Ross DT, Johnsen $H$, Akslen LA, et al: Molecular portraits of human breast tumours. Nature 2000, 406(6797):747-752.

4. Schneider BP, Winer EP, Foulkes WD, Garber J, Perou CM, Richardson A Sledge GW, Carey LA: Triple-negative breast cancer: risk factors to potential targets. Clin Cancer Res 2008, 14(24):8010-8018.

5. Sorlie T, Perou CM, Tibshirani R, Aas T, Geisler S, Johnsen H, Hastie T, Eisen $M B$, Rijn M van de, Jeffrey SS, et al:: Gene expression patterns of breast carcinomas distinguish tumor subclasses with clinical implications. Proceedings of the National Academy of Sciences of the United States of America 2001, 98(19):10869-10874.

6. Sotiriou C, Neo SY, McShane LM, Korn EL, Long PM, Jazaeri A, Martiat P, Fox SB, Harris AL, Liu ET: Breast cancer classification and prognosis based on gene expression profiles from a population-based study. Proceedings of the National Academy of Sciences of the United States of America 2003, 100(18):10393-10398.

7. Weigelt B, Glas AM, Wessels LF, Witteveen AT, Peterse JL, van't Veer LJ: Gene expression profiles of primary breast tumors maintained in distant metastases. Proceedings of the National Academy of Sciences of the United States of America 2003, 100(26):15901-15905.

8. van't Veer LJ, Dai H, Vijver MJ van de, He YD, Hart AA, Mao M, Peterse HL, Kooy K van der, Marton MJ, Witteveen AT, et al:: Gene expression profiling predicts clinical outcome of breast cancer. Nature 2002, 415(6817):530-536

9. Kreike $B$, van Kouwenhove $M$, Horlings $H$, Weigelt $B$, Peterse $H$, Bartelink $H$, Vijver MJ van de: Gene expression profiling and histopathological characterization of triple-negative/basal-like breast carcinomas. Breast Cancer Res 2007, 9(5):R65.

10. Rakha EA, Tan DS, Foulkes WD, Ellis IO, Tutt A, Nielsen TO, Reis-Filho JS: Are triple-negative tumours and basal-like breast cancer synonymous? Breast Cancer Res 2007, 9(6):404. author reply 405

11. Carey LA, Perou CM, Livasy CA, Dressler LG, Cowan D, Conway K, Karaca G, Troester MA, Tse CK, Edmiston S, et al:: Race, breast cancer subtypes, and survival in the Carolina Breast Cancer Study. JAMA 2006, 295(21):2492-2502.

12. Millikan RC, Newman B, Tse CK, Moorman PG, Conway K, Dressler LG, Smith LV, Labbok MH, Geradts J, Bensen JT, et al:: Epidemiology of basallike breast cancer. Breast Cancer Res Treat 2008, 109(1):123-139.

13. Alizadeh AA, Ross DT, Perou CM, Rijn M van de: Towards a novel classification of human malignancies based on gene expression patterns. J Pathol 2001, 195(1):41-52.

14. Rijn M van de, Perou CM, Tibshirani $R$, Haas $P$, Kallioniemi $O$, Kononen J, Torhorst J, Sauter G, Zuber M, Kochli OR, et al:: Expression of cytokeratins 17 and 5 identifies a group of breast carcinomas with poor clinical outcome. Am J Pathol 2002, 161(6):1991-1996.

15. Fadare O, Tavassoli FA: Clinical and pathologic aspects of basal-like breast cancers. Nat Clin Pract Oncol 2008, 5(3):149-159.

16. Peppercorn J, Perou CM, Carey LA: Molecular subtypes in breast cancer evaluation and management: divide and conquer. Cancer investigation 2008, 26(1):1-10.

17. Rakha EA, Reis-Filho JS, Ellis IO: Basal-like breast cancer: a critical review. J Clin Oncol 2008, 26(15):2568-2581.

18. Carey LA, Dees EC, Sawyer L, Gatti L, Moore DT, Collichio F, Ollila DW, Sartor Cl, Graham ML, Perou CM: The triple negative paradox: primary tumor chemosensitivity of breast cancer subtypes. Clin Cancer Res 2007, 13(8):2329-2334

19. Rouzier R, Perou CM, Symmans WF, Ibrahim N, Cristofanilli M, Anderson K, Hess KR, Stec J, Ayers M, Wagner P, et al:: Breast cancer molecular subtypes respond differently to preoperative chemotherapy. Clin Cancer Res 2005, 11(16):5678-5685.

20. Nielsen TO, Hsu FD, Jensen K, Cheang M, Karaca G, Hu Z, HernandezBoussard T, Livasy C, Cowan D, Dressler L, et al: Immunohistochemical and clinical characterization of the basal-like subtype of invasive breast carcinoma. Clin Cancer Res 2004, 10(16):5367-5374.

21. Rakha EA, El-Sayed ME, Green AR, Paish EC, Lee AH, Ellis IO: Breast carcinoma with basal differentiation: a proposal for pathology definition based on basal cytokeratin expression. Histopathology 2007, 50(4):434-438

22. Malumbres $M$, Barbacid M: RAS oncogenes: the first 30 years. Nature reviews 2003, 3(6):459-465

23. Barbacid M: ras genes. Annu Rev Biochem 1987, 56:779-827. 
24. Karnoub AE, Weinberg RA: Ras oncogenes: split personalities. Nat Rev Mol Cell Biol 2008, 9(7):517-531.

25. Niihori T, Aoki Y, Narumi Y, Neri G, Cave H, Verloes A, Okamoto N, Hennekam RC, Gillessen-Kaesbach G, Wieczorek D, et al:: Germline KRAS and BRAF mutations in cardio-facio-cutaneous syndrome. Nature genetics 2006, 38(3):294-296

26. Schubbert S, Zenker M, Rowe SL, Boll S, Klein C, Bollag G, Burgt I van der, Musante L, Kalscheuer V, Wehner LE, et al:: Germline KRAS mutations cause Noonan syndrome. Nature genetics 2006, 38(3):331-336.

27. Karapetis CS, Khambata-Ford S, Jonker DJ, O'Callaghan CJ, Tu D, Tebbutt NC, Simes RJ, Chalchal H, Shapiro JD, Robitaille S, et al.: K-ras mutations and benefit from cetuximab in advanced colorectal cancer. The New England journal of medicine 2008, 359(17):1757-1765.

28. Amado RG, Wolf M, Peeters M, Van Cutsem E, Siena S, Freeman DJ, Juan T, Sikorski R, Suggs S, Radinsky R, et al:: Wild-type KRAS is required for panitumumab efficacy in patients with metastatic colorectal cancer. $J$ Clin Oncol 2008, 26(10):1626-1634

29. Bokemeyer C, Bondarenko I, Makhson A, Hartmann JT, Aparicio J, de Braud F, Donea S, Ludwig H, Schuch G, Stroh C, et al:: Fluorouracil, leucovorin, and oxaliplatin with and without cetuximab in the first-line treatment of metastatic colorectal cancer. J Clin Oncol 2009, 27(5):663-671.

30. De Roock W, Piessevaux H, De Schutter J, Janssens M, De Hertogh G, Personeni N, Biesmans B, Van Laethem JL, Peeters M, Humblet Y, et al: KRAS wild-type state predicts survival and is associated to early radiological response in metastatic colorectal cancer treated with cetuximab. Ann Oncol 2008, 19(3):508-515.

31. Di Fiore F, Blanchard F, Charbonnier F, Le Pessot F, Lamy A, Galais MP, Bastit L, Killian A, Sesboue R, Tuech JJ, et al.: Clinical relevance of KRAS mutation detection in metastatic colorectal cancer treated by Cetuximab plus chemotherapy. British journal of cancer 2007, 96(8):1166-1169.

32. Hoadley KA, Weigman VJ, Fan C, Sawyer LR, He X, Troester MA, Sartor Cl, Rieger-House T, Bernard PS, Carey LA, et al:: EGFR associated expression profiles vary with breast tumor subtype. BMC genomics 2007, 8:258.

33. Khambata-Ford S, Garrett CR, Meropol NJ, Basik M, Harbison CT, Wu S, Wong TW, Huang X, Takimoto CH, Godwin AK, et al:: Expression of epiregulin and amphiregulin and K-ras mutation status predict disease control in metastatic colorectal cancer patients treated with cetuximab. J Clin Oncol 2007, 25(22):3230-3237.

34. Lievre A, Bachet JB, Le Corre D, Boige V, Landi B, Emile JF, Cote JF, Tomasic $G$, Penna C, Ducreux M, et al:: KRAS mutation status is predictive of response to cetuximab therapy in colorectal cancer. Cancer research 2006, 66(8):3992-3995.

35. Van Cutsem E, Kohne CH, Hitre E, Zaluski J, Chang Chien CR, Makhson A, D'Haens G, Pinter T, Lim R, Bodoky G, et al:: Cetuximab and chemotherapy as initial treatment for metastatic colorectal cancer. The New England journal of medicine 2009, 360(14):1408-1417.

36. Klijn JG, Berns PM, Schmitz PI, Foekens JA: The clinical significance of epidermal growth factor receptor (EGF-R) in human breast cancer: a review on 5232 patients. Endocr Rev 1992, 13(1):3-17.

37. Burness ML, Grushko TA, Olopade Ol: Epidermal Growth Factor Receptor in Triple-Negative and Basal-Like Breast Cancer: Promising Clinical Target or Only a Marker? Cancer J 2010, 16(1):23-32.

38. Milanezi F, Carvalho S, Schmitt FC: EGFR/HER2 in breast cancer: a biological approach for molecular diagnosis and therapy. Expert Rev Mol Diagn 2008, 8(4):417-434.

39. Groep P van der, Bouter A, Zanden R van der, Menko FH, Buerger $H$ Verheijen $\mathrm{RH}$, Wall E van der, van Diest PJ: Re: Germline BRCA1 mutations and a basal epithelial phenotype in breast cancer. J Nat/ Cancer Inst 2004, 96(9):712-713. author reply 714.

40. Foulkes WD, Stefansson IM, Chappuis PO, Begin LR, Goffin JR, Wong N, Trudel M, Akslen LA: Germline BRCA1 mutations and a basal epithelial phenotype in breast cancer. J Nat/ Cancer Inst 2003, 95(19):1482-1485.

41. Reis-Filho JS, Milanezi F, Carvalho S, Simpson PT, Steele D, Savage K, Lambros MB, Pereira EM, Nesland JM, Lakhani SR, et al:: Metaplastic breast carcinomas exhibit EGFR, but not HER2, gene amplification and overexpression: immunohistochemical and chromogenic in situ hybridization analysis. Breast Cancer Res 2005, 7(6):R1028-1035.

42. Modjtahedi H, Essapen S: Epidermal growth factor receptor inhibitors in cancer treatment: advances, challenges and opportunities. Anticancer Drugs 2009, 20(10):851-855.
43. Hollestelle A, Elstrodt F, Nagel JH, Kallemeijn WW, Schutte M: Phosphatidylinositol-3-OH kinase or RAS pathway mutations in human breast cancer cell lines. Mol Cancer Res 2007, 5(2):195-201.

44. Jiang Y, Kimchi ET, Staveley-O'Carroll KF, Cheng H, Ajani JA: Assessment of K-ras mutation: a step toward personalized medicine for patients with colorectal cancer. Cancer 2009, 115(16):3609-3617.

45. Plesec TP, Hunt JL: KRAS mutation testing in colorectal cancer. Adv Anat Pathol 2009, 16(4):196-203.

46. Sanchez-Munoz A, Perez-Ruiz E, Jimenez B, Ribelles N, Marquez A, GarciaRios I, Alba Conejo E: Targeted therapy of metastatic breast cancer. Clin Trans/ Oncol 2009, 11(10):643-650.

47. Samuels Y, Wang Z, Bardelli A, Silliman N, Ptak J, Szabo S, Yan H, Gazdar A, Powell SM, Riggins GJ, et al:: High frequency of mutations of the PIK3CA gene in human cancers. Science 2004, 304(5670):554.

48. Hennessy BT, Smith DL, Ram PT, Lu Y, Mills GB: Exploiting the PI3K/AKT pathway for cancer drug discovery. Nat Rev Drug Discov 2005, 4(12):988-1004

49. Jhawer M, Goel S, Wilson AJ, Montagna C, Ling YH, Byun DS, Nasser S, Arango D, Shin J, Klampfer L, et al.: PIK3CA mutation/PTEN expression status predicts response of colon cancer cells to the epidermal growth factor receptor inhibitor cetuximab. Cancer research 2008 68(6):1953-1961.

50. Saal LH, Holm K, Maurer M, Memeo L, Su T, Wang X, Yu JS, Malmstrom PO, Mansukhani M, Enoksson J, et al:: PIK3CA mutations correlate with hormone receptors, node metastasis, and ERBB2, and are mutually exclusive with PTEN loss in human breast carcinoma. Cancer research 2005, 65(7):2554-2559.

51. Li SY, Rong M, Grieu F, lacopetta B: PIK3CA mutations in breast cancer are associated with poor outcome. Breast Cancer Res Treat 2006, 96(1):91-95

52. Kalinsky K, Jacks LM, Heguy A, Patil S, Drobnjak M, Bhanot UK, Hedvat CV, Traina TA, Solit D, Gerald W, et al:: PIK3CA mutation associates with improved outcome in breast cancer. Clin Cancer Res 2009 15(16):5049-5059

53. Campbell IG, Russell SE, Choong DY, Montgomery KG, Ciavarella ML, Hooi CS, Cristiano BE, Pearson RB, Phillips WA: Mutation of the PIK3CA gene in ovarian and breast cancer. Cancer research 2004, 64(21):7678-7681.

54. Lopez-Knowles E, O'Toole SA, McNeil CM, Millar EK, Qiu MR, Crea P, Daly RJ, Musgrove EA, Sutherland RL: PI3K pathway activation in breast cancer is associated with the basal-like phenotype and cancer-specific mortality. Int J Cancer 2010, 126(5):1121-1131.

55. Maruyama N, Miyoshi Y, Taguchi T, Tamaki Y, Monden M, Noguchi S: Clinicopathologic analysis of breast cancers with PIK3CA mutations in Japanese women. Clin Cancer Res 2007, 13(2 Pt 1):408-414.

\section{Pre-publication history}

The pre-publication history for this paper can be accessed here: http://www.biomedcentral.com/1471-2407/10/136/prepub

doi: 10.1186/1471-2407-10-136

Cite this article as: Sánchez-Muñoz et al., Lack of evidence for KRAS oncogenic mutations in triple-negative breast cancer BMC Cancer 2010, 10:136

\section{Submit your next manuscript to BioMed Centra and take full advantage of:}

- Convenient online submission

- Thorough peer review

- No space constraints or color figure charges

- Immediate publication on acceptance

- Inclusion in PubMed, CAS, Scopus and Google Scholar

- Research which is freely available for redistribution 